\title{
Attention-deficit hyperactivity disorder in elementary school students in Shantou, China: prevalence, subtypes, and influencing factors
}

This article was published in the following Dove Press journal:

Neuropsychiatric Disease and Treatment

14 March 2017

Number of times this article has been viewed

\author{
Yanhong Huang' \\ Shaoxiong Zheng' \\ Chongtao $\mathrm{Xu}^{\prime}$ \\ Kun $\operatorname{Lin}^{2}$ \\ Kusheng $\mathrm{Wu}^{2}$ \\ Maochun Zheng' \\ Jie Zhang' \\ Haiyun $\mathrm{Xu}{ }^{\prime}$ \\ 'Mental Health Center, ${ }^{2}$ Department \\ of Preventive Medicine, Shantou \\ University Medical College, \\ Shantou, China
}

\begin{abstract}
Attention-deficit hyperactivity disorder (ADHD) is a frequent childhood-onset psychiatric condition and categorized into three subtypes of predominantly inattentive (ADHD-I), hyperactive impulsive (ADHD-H), and combined (ADHD-C). The prevalence and subtypes of ADHD vary considerably. The primary aim of this study was to provide a prevalence estimate of ADHD in elementary school students living in Shantou, a district of China, and in addition to examine the influence of informants, age, and gender on the prevalence. A total of 3,497 students aged 7-12 years were enrolled by random and stratified sampling. In stage I, teachers and parents of all participating students in randomly selected schools were asked to complete Chinese versions of the Conners' 10 -item scale. In stage II, students with high scores $(>15)$ were interviewed by a psychiatrist for a diagnosis with or without ADHD. Parents rated many more students with high scores than teachers did in stage I. The prevalence of ADHD determined by Diagnostic and Statistical Manual of Mental Disorders, fifth edition (DSM-5) was 5.91\% $(5.27 \%-6.55 \%)$, which is comparable to the rates reported in previous studies with Chinese children. This hits the low border of the ADHD prevalence range from 5.9 to $7.1 \%$ worldwide, and is lower than that of Chinese children living in Hong Kong, suggesting an important influence of Chinese culture on the diagnosis of ADHD. The constituent ratios of ADHD-I, ADHD-C, and ADHD-H subtypes were $67.43,24.57$, and $8.00 \%$, respectively. The rate of ADHD-H decreased with age, whereas that of ADHD-I remained at the highest levels in all age groups, suggesting that symptoms in the inattention domain are the most persistent and refractory.
\end{abstract}

Keywords: adolescents, ADHD, prevalence, Chinese culture, informants

\section{Introduction}

Attention-deficit hyperactivity disorder (ADHD) is one of the most frequent childhoodonset psychiatric conditions and characterized by persistent inattention, hyperactivity, and impulsivity, which are pervasive and lead to various degrees of functional impairment. This disorder imposes an enormous burden on society as the consequences of psychological dysfunction, adverse vocational outcomes, stress on families, and societal financial costs. ${ }^{1,2}$ During the past 3 decades, a number of studies have reported the prevalence rates of ADHD. In 2007, Polanczyk et al published a comprehensive review of the literature on the prevalence of ADHD, which included 102 studies. A meta-analysis resulted in a pooled prevalence of 5.29\% (95\% confidence interval [CI] 5.01-5.56) and identified the main factors contributing to the variability of estimates, including diagnostic criteria, source of information for reporting the symptoms, and requirement of functional impairment for the diagnosis. ${ }^{3}$ However, study location seemed to have no significant effect on the estimate, as claimed in the study by the Centers for Disease Control and Prevention,
Correspondence: Chongtao Xu; Haiyun Xu

Mental Health Center, Shantou University Medical College, North Taishan

Road, Shantou, Guangdong Province 515065, China

Email ctxu@vip.sina.com; hyxu@stu.edu.cn 
which reported a $9.5 \%$ prevalence of ADHD in the USA. ${ }^{4}$ In a recent comprehensive review, which included studies published after 2007, the meta-analysis results generated estimates of ADHD in children and adolescents ranging from 5.9 to $7.1 \%{ }^{5}$ Although significant heterogeneity existed between estimates, once again, the study location did not explain the variability, supporting the claim in the previous review by Polanczyk et al. ${ }^{3}$ In line with these previous findings, a more recent updated systematic review concluded that variability in ADHD prevalence estimates is significantly associated with methodological characteristics, including source of information, impairment criterion, and diagnostic criteria, instead of geographical location. ${ }^{6}$ In spite of the abovementioned achievements in the epidemiology of ADHD, further studies are still necessary to assess the prevalence estimates of ADHD, examine the influences of culture and related factors on the prevalence, and assess the functional impairments of ADHD children in developing countries, which were underrepresented in the most comprehensive reviews of the ADHD epidemiology in youths. Of the developing countries, China deserves to be highlighted for its biggest population of children living in such a huge area with diversity in geography and culture. While recent studies with ADHD children in China addressed the genetic and environmental influences on ADHD, ${ }^{7-12}$ family risk factors for ADHD, ${ }^{13}$ and psychological and social interventions of $\mathrm{ADHD},{ }^{14,15}$ there is a relative shortage of epidemiological studies on ADHD in China.

Of the few previous epidemiological studies on ADHD in China, a recent study reported an overall prevalence of Diagnostic and Statistical Manual of Mental Disorders, forth edition (DSM-IV) disorders of $9.49 \%(95 \% \mathrm{CI}=8.10 \%-11.10 \%)$ among children and adolescents in Northeast China, in which the prevalence of ADHD was $0.84 \%(95 \% \mathrm{CI}=0.52 \%-1.36 \%) .{ }^{16}$ Both the rates are much lower than the values of the same variables (16.4 and 3.9\%, respectively) reported by a previous study with Chinese adolescents in Hong Kong ${ }^{17}$ and lower than the worldwide-pooled prevalence of mental disorders (13.9\%; $95 \%$ $\mathrm{CI}=11.3 \%-15.9 \%)$ and $\mathrm{ADHD}(3.4 \%$; 95\% CI $=2.6 \%-4.5 \%)$ determined by a recent meta-analysis by Polanczyk et al. ${ }^{18}$ Although the big difference between the reported prevalence of ADHD in China and the worldwide-pooled prevalence of ADHD may be mainly due to methodological factors as reviewed earlier, a possibility that Chinese children have a lower prevalence of ADHD could not be ruled out. In line with this speculation, another recent epidemiological study, ${ }^{19}$ which surveyed a total of 15,412 students aged 5-15 years from 12 kindergartens, 13 primary schools, and nine junior secondary schools in the Zhabei District of Shanghai, reported an ADHD prevalence of $4.6 \%$, being lower than the worldwide-pooled prevalence of $5.29 \%$ reported by Polanczyk et al. ${ }^{3}$ The primary aim of this study was to provide a prevalence estimate of ADHD in elementary school students living in Shantou, a district of China, with unique sociodemographic features such as relatively large families with three or more generations living together and low education levels. No information was available on the prevalence of ADHD in this district. We hypothesized that a large family environment would decrease the prevalence of ADHD. For the diagnosis of ADHD, we applied Diagnostic and Statistical Manual of Mental Disorders, fifth edition (DSM-5) in this study, which changed the onset of the ADHD symptoms from not older than 7 (defined in DSM-IV) to 12 years. In addition, we examined the influences of informants, age, and gender on the prevalence estimates of ADHD.

\section{Methods}

\section{Selection of participants}

This study was performed in the two urban districts of Longhu and Jinping, Shantou, China, between September 2013 and April 2014. On the basis of the primary study, the theoretical sample size of this study was calculated to be 2,793 students. In practice, four schools were enrolled by random sampling from 73 public primary schools in the city; whereas five private primary schools were excluded as the students in them were kids of temporary habitants with more heterogeneous cultural backgrounds. Then, 40 or $50 \%$ classes of grades 2-6 of these four schools were randomly selected. Once a class was selected, all students in it would be qualified to participate in the study. Grade 1 students were not included as September is the first month of a new school year and the students were still adapting to the school environment. All students in the selected classes were aged in the range of 7-12 years. The total number of grades 2-6 students in these four schools was 7,151, of whom 3,497 students were selected to participate in stage I of this study.

\section{Assessment}

A two-stage procedure was performed. Prior to stage I, a workshop on ADHD was scheduled for participating students and teachers to explain the research procedures and to secure teachers' and parents' consent to participate. In stage I, teachers and parents of all eligible participating students were asked to complete Chinese versions of the Conners' 10-item scale. The Conners' 10 -item scale consists of 10 statements for which a parent or a teacher rates a child's behavior on a 4-point Likert scale, ranging from 0 to 3. It discriminated very well between children with and without ADHD and thus has been used as a valid screening instrument for the identification of $\mathrm{ADHD}^{20}$ and has been used to measure the 


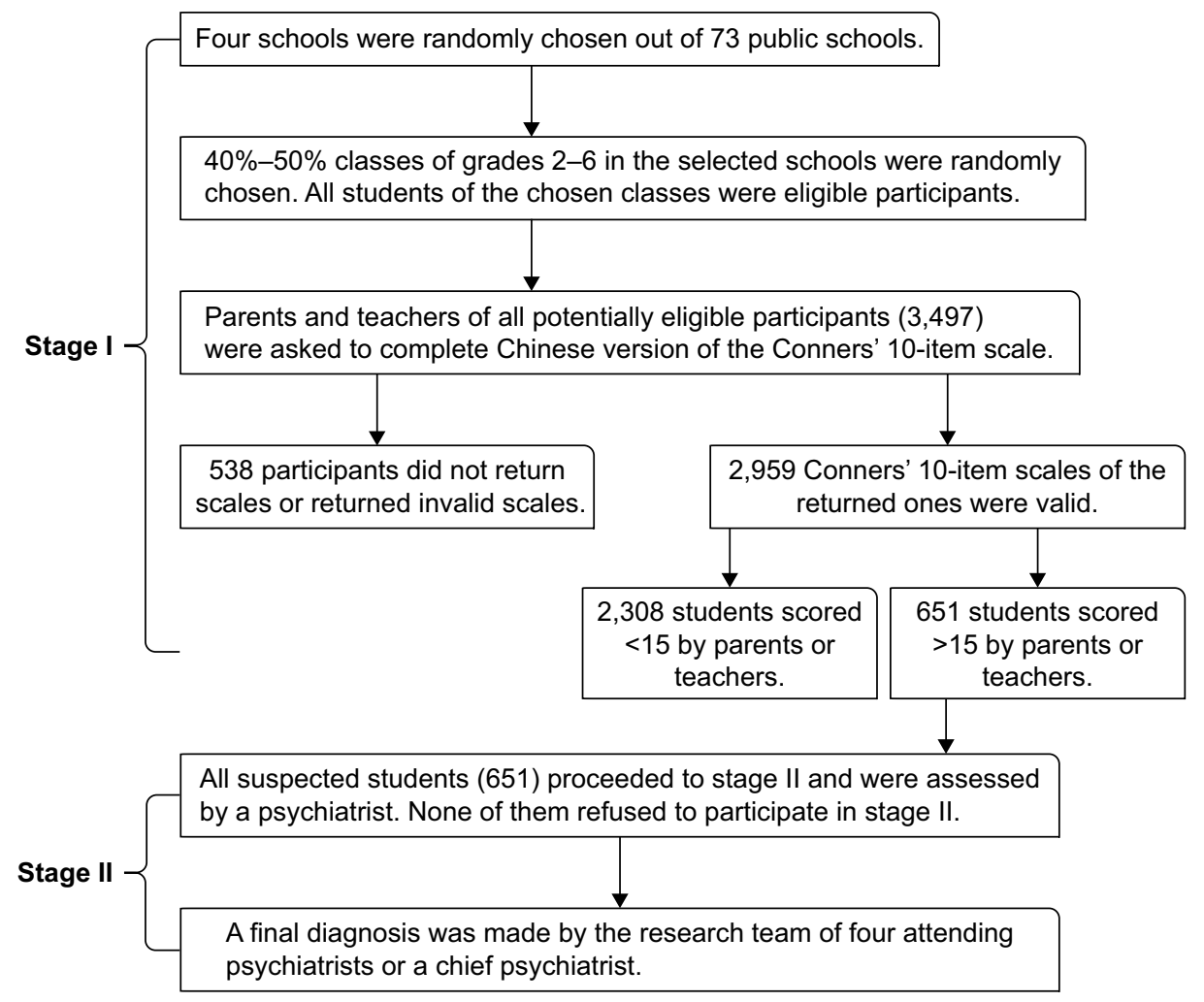

Figure I Flowchart showing the two-stage procedures of sampling and diagnosis of ADHD. Abbreviation: ADHD, attention-deficit hyperactivity disorder.

behavioral problems of ADHD children in China. ${ }^{21}$ In stage II, students who were suspected to have ADHD on the basis of the Conners' 10-item scale scores, given by either parents or teachers, were subjected to a structured interview with a psychiatrist of the research team, consisting of four attending psychiatrists, in the presence of parents, for a diagnosis with or without ADHD according to the DSM-5 criteria. A final diagnosis was made if all the four doctors had reached a consensus, otherwise, the diagnoses would be referred to a chief psychiatrist (CX) to achieve a final conclusion. The flow diagram of the procedures is shown in Figure 1.

The protocol of this study was reviewed and approved by the Ethics Committee of Shantou University Medical College. Each school head was advised and agreed to participate in the study. Each of the parents and teachers of all eligible potential participants signed written informed consent and provided written permission to share results for this study.

\section{Diagnosis of ADHD}

For the Conners' 10-item scale scores, a same cutoff point of $\geq 15$ was set up for parents and teachers. This cutoff point is the same as that used by Sprague et $\mathrm{al}^{22}$ but higher than that used by Landgren et al. ${ }^{23}$ According to parents, 651 students had the Conners' 10 -item scale scores $>15$. The number generated from teachers' assessment was 392.
All these students and their parents were invited to participate in stage II of the study. The diagnosis criteria of ADHD described in DSM-5 were followed during the diagnosis process. Exclusionary criteria included mental retardation, major medical neurological disorders, psychoses, bipolar disorder, and major depressive disorder with symptoms starting prior to ADHD. However, the subtypes of ADHD were defined by following the criteria of Diagnostic and Statistical Manual of Mental Disorders, fourth edition, text revision (DSM-IV-TR) (association Academy of Psychosomatic Medicine). ${ }^{24}$

\section{Data analysis}

Data were entered into the EpiData 3.1 software and analyzed using SPSS v16.0 (IBM Corp., Armonk, NY, USA). The chi-square test was performed to compare the rates of suspected ADHD students determined by Conners' 10-item scale by parents and teachers, to compare the prevalence rates of ADHD diagnosed by DSM-5 in different age groups, and to compare the ratio of each ADHD subtype defined by DSM-IV-TR. Significant $P$-values were set $\leq 0.05$.

\section{Results}

\section{Demographic data of the participants}

The students were included in analyses only if both the parent and teacher scales were returned and they were correctly 
Table I Age and gender distributions of the study subjects

\begin{tabular}{|c|c|c|c|c|c|c|}
\hline \multirow{3}{*}{$\begin{array}{l}\text { Age group } \\
\text { (years) }\end{array}$} & \multicolumn{4}{|c|}{ Gender } & \multirow[t]{3}{*}{ Total } & \multirow[t]{3}{*}{$\%$} \\
\hline & \multicolumn{2}{|l|}{ Male } & \multicolumn{2}{|c|}{ Female } & & \\
\hline & $\mathbf{N}$ & $\%$ & $\mathbf{N}$ & $\%$ & & \\
\hline 7 & 230 & 48.7 & 242 & 51.3 & 472 & 15.95 \\
\hline 8 & 331 & 51.2 & 315 & 48.8 & 646 & 21.83 \\
\hline 9 & 326 & 54.0 & 278 & 46.0 & 604 & 20.41 \\
\hline 10 & 251 & 50.9 & 242 & 49.1 & 493 & 16.66 \\
\hline II & 270 & 48.7 & 284 & 51.3 & 554 & 18.72 \\
\hline 12 & 101 & 53.2 & 89 & 46.8 & 190 & 6.42 \\
\hline Total & 1,509 & 51 & 1,450 & 49 & 2,959 & 100 \\
\hline
\end{tabular}

filled out. Of the 3,497 enrolled students, 2,959 students were included in the screening phase and the overall response rate was $85 \%$. This number is greater than the theoretical sample size of 2,793. The age and gender distributions of the participants are listed in Table 1.

\section{Positively screened students according to the Conners' 10-item scale}

The results of the Conners' 10 -item scale scores according to parents and teachers are listed in Tables 2 and 3. According to parents, the average rate of high-score students was $22 \%$, which is significantly higher than the rate of $13.25 \%$ according to teachers. For both male and female students, parents rated many more students with high scores (male, 28.89 vs $18.03 \%$; female, 14.83 vs $8.28 \%$ ) than teachers did. It is clear that the rate in male students was significantly higher than that in females according to either parents or teachers (Table 2). With respect to each item of the Conners' 10-item scale, except for the item of disturbing other children, many more students were highly scored by parents on all other items than those by teachers (Table 3). The sensitivity, specificity, and positive predictive value of the positively screened students by parents were $94.86,36$, and $26.88 \%$, respectively. For the positively screened students by teachers, the values of the same variables were $97,78.88$, and $44.64 \%$, respectively.

\section{The prevalence of ADHD according to DSM-5}

Of the high-score students, 175 students met the DSM-5 diagnosis criteria for ADHD. The overall prevalence of

Table 2 Distribution of positively screened students by gender

\begin{tabular}{llllllll}
\hline \multirow{2}{*}{ Gender } & \multicolumn{2}{l}{ Parents } & & \multicolumn{2}{l}{ Teachers } & \multirow{2}{*}{$\chi^{2}$} & P-value \\
\cline { 2 - 3 } & N & $\%$ & & N & $\%$ & & \\
\hline Male & 436 & 28.89 & & 272 & 18.03 & 75.98 & $<0.00 \mathrm{I}$ \\
Female & 215 & 14.83 & & 120 & 8.28 & 53.88 & $<0.00 \mathrm{I}$ \\
Total & $65 \mathrm{I}$ & 22.00 & & 392 & 13.25 & 128.63 & $<0.00 \mathrm{I}$ \\
\hline
\end{tabular}

Notes: Gender difference: parents: $\chi^{2}=150.05, P<0.001$ and teachers: $\chi^{2}=117.88$, $P<0.00$ I.
Table 3 Comparisons of (Conners' 10-item scale) positively screened students by parents and teachers

\begin{tabular}{|c|c|c|c|c|c|c|}
\hline \multirow[t]{2}{*}{ Items } & \multicolumn{2}{|c|}{$\begin{array}{l}\text { Parents' } \\
\text { rating }\end{array}$} & \multicolumn{2}{|c|}{$\begin{array}{l}\text { Teachers' } \\
\text { rating } \\
\end{array}$} & \multirow[t]{2}{*}{$\chi^{2}$} & \multirow[t]{2}{*}{$P$-value } \\
\hline & $\mathbf{N}$ & $\%$ & $\mathbf{N}$ & $\%$ & & \\
\hline Restless or overactive & 543 & 18.35 & 293 & 9.90 & 87.06 & $<0.001$ \\
\hline Excitable, impulsive & 597 & 20.18 & 323 & 10.92 & 96.63 & $<0.001$ \\
\hline Disturbs other children & 182 & 6.15 & 189 & 6.39 & 0.14 & 0.710 \\
\hline Short attention span & 916 & 30.96 & 532 & 17.97 & 134.82 & $<0.001$ \\
\hline Constantly fidgeting & 449 & 15.17 & 319 & 10.78 & 25.29 & $<0.001$ \\
\hline Easily distracted & 662 & 22.37 & 336 & 11.35 & 103.47 & $<0.001$ \\
\hline Easily frustrated & 442 & 14.94 & 166 & 5.61 & 139.64 & $<0.001$ \\
\hline Cries often and easily & 450 & $|5.2|$ & 319 & 10.78 & 25.29 & $<0.001$ \\
\hline Mood changes quickly & 369 & 12.47 & 180 & 6.08 & 71.72 & $<0.001$ \\
\hline Temper outbursts & 210 & 7.10 & $13 \mid$ & 4.42 & 19.42 & $<0.001$ \\
\hline
\end{tabular}

ADHD in the whole sample was $5.91 \%$. All four participating schools showed comparable prevalence rates $(6.29,5.88$, 6.74 , and $5.20 \%$, respectively), which resulted in a $95 \% \mathrm{CI}$ of $5.27 \%-6.55 \%$. Male and female students showed significantly different rates of 8.75 and $3.0 \%$, respectively, and the rates in different age groups were also different. Specifically, the prevalence rates in 7- and 11-year-old children were significantly lower compared to the other groups showing comparable higher prevalence rates. The highest rate was seen in the 9-year-old group (Table 4).

\section{The subtypes of ADHD}

Of the 175 ADHD students, the respective constituent ratios of ADHD-I, ADHD-C, and ADHD-H were 67.43, 24.57, and $8.00 \%$, respectively. Males and females showed comparable constituent ratios of each subtype (Table 5). However, the prevalence rates of the three subtypes vary with age. Specifically, the 7-year-old group showed the lowest prevalence of ADHD-I and the highest prevalence of ADHD-C, the 10-year-old group showed the highest prevalence of ADHD-I but the lowest rate of ADHD-C, and the 11-year-old group showed the lowest prevalence of ADHD-H (Table 6).

Table 4 Distribution of ADHD prevalence according to age

\begin{tabular}{llll}
\hline Age (years) & Sample size $(\mathbf{n})$ & \multicolumn{2}{l}{$\begin{array}{l}\text { Prevalence } \\
\text { of ADHD }\end{array}$} \\
\cline { 3 - 4 } & & $\mathbf{N}$ & $\%$ \\
\hline 7 & 472 & 22 & 4.66 \\
8 & 646 & 39 & 6.03 \\
9 & 604 & 44 & 7.28 \\
10 & 493 & 33 & 6.69 \\
II & 554 & 25 & 4.51 \\
I2 & 190 & 12 & 6.31 \\
Total & 2,959 & 175 & 5.91 \\
\hline
\end{tabular}

Notes: Groups $\chi^{2}=5.285 ; d f=5 ; P=0.382$.

Abbreviation: ADHD, attention-deficit hyperactivity disorder. 
Table 5 Distribution of ADHD subtypes by gender

\begin{tabular}{lllllll}
\hline Gender & ADHD-I & ADHD-H & ADHD-C & Total & $\chi^{2}$ & P-value \\
\hline Male & $87(65.9 I)$ & II (8.33) & $34(25.76)$ & $132(100)$ & 103.57 & $<0.001$ \\
Female & $31(72.09)$ & $3(6.98)$ & $9(20.93)$ & $43(100)$ & 43.49 & $<0.001$ \\
Total & $118(67.43)$ & $14(8.00)$ & $43(24.57)$ & $175(100)$ & 148.13 & $<0.001$ \\
\hline
\end{tabular}

Notes: Data are expressed as number (\%). Gender difference: ADHD-I: $\chi^{2}=53.15, P<0.001$; ADHD-H: $\chi^{2}=9.14, P=0.002 ;$ ADHD-C: $\chi^{2}=29.07, P<0.00$ I; and total: $\chi^{2}=90.53, P<0.001$.

Abbreviations: ADHD, attention-deficit hyperactivity disorder; ADHD-H, attention deficit hyperactivity disorder, predominantly hyperactive type; ADHD-I, attention deficit hyperactivity disorder, predominantly inattentive type; ADHD-C, attention deficit hyperactivity disorder, predominantly combined type.

\section{Discussion}

This study provided the prevalence estimates of ADHD in elementary school students living in the urban area of Shantou, China, by using a two-stage procedure. In stage I, teachers and parents of all participating students were asked to complete Chinese versions of the Conners' 10-item scale, whereas the diagnosis of ADHD was made according to DSM-5 in stage II. The rates of high-score students according to parents and teachers were 22.00 and $13.25 \%$, respectively. Both rates were significantly higher than the prevalence of 5.91\% according to DSM-5. The data reported here are consistent with the common impression: studies without the use of functional impairment criteria have widely varied prevalence rates of ADHD. Previous examples supporting this impression are as follows: Cornejo et $\mathrm{al}^{25}$ reported a prevalence of $15.8 \%$ using the Conners' rate scale, and Bener et $\mathrm{al}^{26}$ found an overall prevalence rate of $9.4 \%$ among primary school children in an Arabian society rated by school teachers according to Swanson, Nolan, and Pelham Rating Scale, fourth version (SNAP-IV), but when the full DSM-IV diagnosis criteria for ADHD were applied, the prevalence figures tended to be lower and fairly uniform, as reported by Wolraich et $\mathrm{al}^{27}$ in the USA: the prevalence rates in Tennessee County were $16.1 \%$ without the use of impairment criterion and $6.8 \%$ when impairment was taken into consideration.

On the Conners' 10 -item scale, the rate of positively screened students by parents was higher $(22.00 \%)$ than that by teachers $(13.25 \%)$. The rate according to parents here is comparable to that reported in a previous study in which up to $19 \%$ of children in Qatar (6-12-year-old children in government schools) had moderate to high levels of ADHD according to the Conners' 10 -item scale. ${ }^{26}$ In explaining the difference between the estimates by parents and teachers in the present study, it should not be ignored that parents were more heterogeneous in terms of education level and knowledge about ADHD compared to teachers. The latter might use the information given by the workshop on ADHD more accurately and comprehend the research procedures more completely than parents. This may make parents more sensitive to ADHD-related behaviors in children. In support of this speculation, another previous study reported a higher mean score of ADHD children on the Conners' 10-item scale according to parents and a lower one according to teachers, although the two informants gave comparable scores for children without a diagnosis of ADHD. ${ }^{20}$ Another possible influencing factor is the one-child family environment, which is now the dominant family type in China. A child is the most precious person in the one-child family and thus is protected and looked after by all the other family members. This family environment likely provided a platform for a child to act out ADHD-relevant behaviors. Indeed, parents assigned high scores to many more students on almost all items of the Conners' 10-item scale than teachers did. The only exception is the item of disturbing other children. Certainly, this behavior is unlikely to happen, or seldom happens, in a one-child family.

Of the student sample in this study, 175 students were diagnosed as ADHD according to DSM-5, resulting in an overall prevalence rate of $5.91 \%$ with a $95 \%$ CI of $5.27 \%-6.55 \%$.

Table 6 Distribution of ADHD subtypes according to age

\begin{tabular}{lllllll}
\hline Age (years) & ADHD-I & ADHD-H & ADHD-C & Total & $\chi^{2}$ & P-value \\
\hline 7 & $10(45.46)$ & $1(4.55)$ & $11(50.00)$ & $22(100)$ & 12.41 & 0.002 \\
8 & $26(66.67)$ & $4(10.26)$ & $9(23.08)$ & $39(100)$ & 30.69 & $<0.001$ \\
9 & $27(61.36)$ & $6(13.64)$ & $11(25.00)$ & $44(100)$ & 24.61 & $<0.001$ \\
10 & $27(81.82)$ & $2(6.06)$ & $4(12.12)$ & $33(100)$ & 52.64 & $<0.001$ \\
11 & $17(68.00)$ & $1(4.00)$ & $7(28.00)$ & $25(100)$ & 23.52 & $<0.001$ \\
12 & $11(91.67)$ & $0(0)$ & $1(8.33)$ & $12(100)$ & 16.67 & $<0.001$ \\
Total & $118(67.43)$ & $14(8.00)$ & $43(24.57)$ & $175(100)$ & 148.13 & $<0.001$ \\
\hline
\end{tabular}

Notes: Data are expressed as number (\%). Age difference: ADHD-I: $\chi^{2}=19.73, P=0.001$; ADHD-H: $\chi^{2}=7.41, P=0.097$; ADHD-C: $\chi^{2}=13.54, P=0.019$; and total: $\chi^{2}=28.59, P<0.001$.

Abbreviations: ADHD, attention-deficit hyperactivity disorder; ADHD-H, attention deficit hyperactivity disorder, predominantly hyperactive type; ADHD-I, attention deficit hyperactivity disorder, predominantly inattentive type; ADHD-C, attention deficit hyperactivity disorder, predominantly combined type. 
This rate hits the low border of the prevalence range from 5.9 to $7.1 \%$ of children worldwide, ${ }^{5}$ is in the lowest one-third of the range from 5 to $8 \%$ in USA, ${ }^{28}$ and is much lower than the estimates between 11 and 16\% generated from the application of DSM-IV criteria to school populations in previous epidemiological studies. ${ }^{29}$ This is in contrast to our expectation of a higher prevalence as the consequence of applying DSM-5, which changed the onset of the ADHD symptoms from not older than 7 (defined in DSM-IV) to 12 years. Two inferences from this unexpected result are as follows: 1) the change in the definition of the onset of the ADHD symptoms has no significant impact on the estimation of the prevalence of ADHD in elementary school students, and 2) Chinese culture significantly contributed to the relatively lower prevalence reported in this study. In support of the first inference, a previous study reported that extending the ageof-onset criterion to 12 years resulted in a negligible increase in ADHD prevalence by $0.1 \%$. Children who first manifested ADHD symptoms between ages 7 and 12 years did not present correlates or risk factors that were significantly different from children who manifested symptoms before the age of 7 years. ${ }^{30}$ In support of the second inference, Jin et al ${ }^{19}$ reported an ADHD prevalence of $4.6 \%$ in Shanghai, Zhou et $\mathrm{al}^{31}$ reported a rate of $5.39 \%$ among the primary school students in Shenzhen (Guangdong Province, China), and Guan et $\mathrm{al}^{32}$ reported an ADHD prevalence of $5.95 \%$ in primary and middle school students in Hunan Province. All these three studies applied DSM-IV criteria for the diagnosis of ADHD. Moreover, the prevalence of ADHD among the elementary school students in Guilin (Guangxi, China) was $4.25 \%{ }^{33}$ These lower rates were reported on children living in different regions of China, suggesting that Chinese culture, instead of study location, was the dominant factor significantly influencing the diagnosis of ADHD. In support of this suggestion, a previous study reported an ADHD prevalence of $8.9 \%$ in Chinese students living in Hong Kong, ${ }^{34}$ where people may be more significantly affected by Western civilization. Together, these previous studies and the present study suggest an important impact of Chinese culture on the prevalence of ADHD in children. In line with this suggestion, previous studies from other parts of the world have shown that culture in general may influence the identification and interpretation of symptoms and the meaning attributed to them, not only by parents and teachers but also by health professionals. ${ }^{35-39}$ Moreover, culture and related factors that are more proximal to childhood development (eg, parental style) influence the emergence of emotional and behavioral problems. ${ }^{40-42}$ Nevertheless, future studies with larger samples are needed to address specific potential factors in Chinese culture that may contribute to the relatively lower prevalence of ADHD in children living in the mainland of China.

The gender odds ratio (OR) (male/female) for ADHD diagnosed by DSM-5 in this study is $\sim 3(8.75 \%$ vs $3 \%$ ), adding to the pool of data claiming that ADHD is more common in male children. ${ }^{5,29,43,44}$ The male predominance probably reflects both referral bias and a true gender difference in prevalence as explained by Rowland et al. ${ }^{45}$

As expected, the prevalence of ADHD varied with age. In the age range of 7-12 years, 9-year-old children showed the highest prevalence rate $(7.28 \%)$ and the lowest rates were seen in the 7-year-old (4.66\%) and 11-year-old (4.51\%) groups. This profile is in line with that reported by a recent study, in which the highest prevalence (9.4\%) of ADHD was seen in 9-year-old children whereas the rates in the 7-yearand 12-year-old groups were 6.9 and $6.4 \%$, respectively. ${ }^{46}$ This profile, in addition to indicating a spontaneous disappearance of some ADHD symptoms, is also in line with the curve of academic pressure experienced by primary school students in China, suggesting an amplifying effect of mental pressure on the symptoms of ADHD. The rate rebounded from $4.51 \%$ in the 11 -year-old group to $6.31 \%$ in the 12 -yearold students, adding supporting evidence for this suggestion of added mental pressure. More pertinent supporting evidence is as follows: reading disability was suggested to lead to the development of ADHD symptoms, possibly as a result of academic failure, as experienced, by a child in an early study, ${ }^{47}$ and learning disorders such as dyscalculia ${ }^{48}$ and reading ${ }^{49}$ contributed to the prediction of ADHD.

ADHD-I is the most common subtype followed by ADHD-C and ADHD-H in both males and females in the present study. This order is in line with that summarized in a meta-analytic review by Willcutt. ${ }^{5}$ The same order was also reported in a recent community survey of ADHD among primary school pupils in Nigeria, ${ }^{46}$ although some earlier studies reported an order of ADHD-C, ADHD-I, and ADHD-H. ${ }^{27,50,51}$ Interestingly, the prevalence of ADHD-H decreased to the lowest levels in 11- and 12-year-old children, while ADHD-I remained at higher levels. This is consistent with the profile of prevalence change over age indicating a spontaneous disappearance of some ADHD symptoms, as discussed earlier. In line with this result, it was noticed that the more overt symptoms of hyperactivity/impulsivity tended to wane early in life, whereas the more covert symptoms of inattention tended to persist over time. ${ }^{52}$ Together, these results suggest that symptoms in the inattention domain may be more persistent and refractory than the other symptoms in ADHD patients. 


\section{Conclusion}

The Conners' 10-item scale produced higher prevalence estimates compared to DSM-5, suggesting an effect of instrument on the prevalence of ADHD. Parents rated higher scores on all items of the Conners'-10 item scale than teachers did, indicating an effect of informant. The prevalence estimate of $5.91 \%$ according to DSM-5 is in the range of ADHD prevalence rates reported in previous studies by other Chinese investigators, but is lower than that of Hong Kong children, suggesting a significant effect of Chinese culture. The profile of prevalence change over age indicates a spontaneous disappearance of some ADHD symptoms and suggests an amplifying effect of mental pressure on the symptoms of ADHD. Of the diagnosed ADHD students, the overall constituent ratios of ADHD-I, ADHD-C, and ADHD-H subtypes were $67.43,24.57$, and $8.00 \%$, respectively, but the rate of ADHD-H decreased with age, whereas that of ADHD-I remained at the highest levels in the six age groups, suggesting that symptoms in the inattention domain are the most persistent and refractory in ADHD patients.

\section{Acknowledgments}

The authors thank all participating teachers, students, and their parents for their cooperation, and time spent on the survey. This study was financially supported by Li Ka Shing Foundation and Shantou Science and Technology Bureau (441315630128).

\section{Author contributions}

SZ, CX, and HX designed and supervised the study. YH carried out analysis and interpreted the data. $\mathrm{MZ}$ and $\mathrm{JZ}$ assisted in the design, analysis, and interpretation of the data. KL and KW performed the statistical analysis of data. YH and HX wrote and revised the article. All authors contributed toward data analysis, drafting and critically revising the paper and agree to be accountable for all aspects of the work.

\section{Disclosure}

The authors report no conflicts of interest in this work.

\section{References}

1. Biederman J, Faraone SV. Attention-deficit hyperactivity disorder. Lancet. 2005;366(9841):237-248.

2. Polanczyk G, Jensen P. Epidemiologic considerations in attention deficit hyperactivity disorder: a review and update. Child Adolesc Psychiatr Clin N Am. 2008;17:245-260.

3. Polanczyk G, de Lima MS, Horta BL, Biederman J, Rohde LA. The worldwide prevalence of ADHD: a systematic review and meta-regression analysis. Am J Psychiatry. 2007;164(6):942-948.

4. Visser SN, Bitsko RH, Danielson ML, Perou R, Blumberg SJ. Increasing prevalence of parent-reported attention-deficit/hyperactivity disorder among children-United States, 2003 and 2007. Morb Mortal Wkly Rep. 2010;59:1439-1443.
5. Willcutt EG. The prevalence of DSM-IV attention-deficit/hyperactivity disorder: a meta-analytic review. Neurotherapeutics. 2012;9(3): 490-499.

6. Polanczyk GV, Willcutt EG, Salum GA, Kieling C, Rohde LA. ADHD prevalence estimates across three decades: an updated systematic review and meta-regression analysis. Int J Epidemiol. 2014;43(2):434-442.

7. Chen TJ, Ji CY, Wang SS, Lichtenstein P, Larsson H, Chang Z. Genetic and environmental influences on the relationship between ADHD symptoms and internalizing problems: a Chinese twin study. Am J Med Genet B Neuropsychiatr Genet. 2016;171(7):931-937.

8. Jin J, Liu L, Gao Q, et al. The divergent impact of COMT Val158Met on executive function in children with and without attention-deficit/ hyperactivity disorder. Genes Brain Behav. 2016;15(2):271-279.

9. Liu L, Cheng J, Li H, Yang L, Qian Q, Wang Y. The possible involvement of genetic variants of NET1 in the etiology of attention-deficit/ hyperactivity disorder comorbid with oppositional defiant disorder. J Child Psychol Psychiatry. 2015;56(1):58-66.

10. Sun GX, Wang BH, Zhang YF. Relationship between serum zinc levels and attention deficit hyperactivity disorder in children. Zhongguo Dang Dai Er Ke Za Zhi. 2015;17(9):980-983.

11. Xu Y, Chen XT, Luo M, et al. Multiple epigenetic factors predict the attention deficit/hyperactivity disorder among the Chinese Han children. J Psychiatr Res. 2015;64:40-50.

12. Zhang R, Huo X, Ho G, et al. Attention-deficit/hyperactivity symptoms in preschool children from an E-waste recycling town: assessment by the parent report derived from DSM-IV. BMC Pediatr. 2015;15:51.

13. Zhang YF, Sun GX. A meta analysis of family risk factors for attention deficit hyperactivity disorder. Zhongguo Dang Dai Er Ke Za Zhi. 2015;17(7):721-725.

14. Bai GN, Wang YF, Yang L, Niu WY. Effectiveness of a focused, brief psychoeducation program for parents of ADHD children: improvement of medication adherence and symptoms. Neuropsychiatr Dis Treat. 2015;11:2721-2735.

15. Lo HH, Wong SY, Wong JY, Wong SW, Yeung JW. The effect of a family-based mindfulness intervention on children with attention deficit and hyperactivity symptoms and their parents: design and rationale for a randomized, controlled clinical trial (Study protocol). BMC Psychiatry. 2016;16:65.

16. Xiaoli Y, Chao J, Wen P, et al. Prevalence of psychiatric disorders among children and adolescents in northeast China. PLoS One. 2014; 9(10):e111223.

17. Leung PWL, Hung S, Ho T, et al. Prevalence of DSM-IV disorders in Chinese adolescents and the effects of an impairment criterion: a pilot community study in Hong Kong. Eur Child Adolesc Psychiatry. 2008; 17(7):452-461.

18. Polanczyk GV, Salum GA, Sugaya LS, Caye A, Rohde LA. Annual research review: a meta-analysis of the worldwide prevalence of mental disorders in children and adolescents. $J$ Child Psychol Psychiatry. 2015;56(3):345-365.

19. Jin W, Du Y, Zhong X, David C. Prevalence and contributing factors to attention deficit hyperactivity disorder: a study of five-to fifteenyear-old children in Zhabei District, Shanghai. Asia Pac Psychiatry. 2014;6(4):397-404.

20. Westerlund J, Ek U, Holmberg K, Naswall K, Fernell E. The Conners' 10-item scale: findings in a total population of Swedish 10-11-year-old children. Acta Paediatr. 2009;98(5):828-833.

21. Chen L, Huang X, Lei D, et al. Microstructural abnormalities of the brain white matter in attention-deficit/hyperactivity disorder. $J$ Psychiatry Neurosci. 2015;40:280-287.

22. Sprague RL, Cohen MN, Werry JS. Normative data on the Conners' Teacher Rating Scale and Abbreviated Scale. Technical Report, Institute of Child Behavior and Development. Champaign: University of Illinois; 1974.

23. Landgren M, Pettersson R, Kjellman B, Gillberg C. ADHD, DAMP and other neurodevelopmental/psychiatric disorders in 6-year-old children: epidemiology and co-morbidity. Dev Med Child Neurol. 1996;38(10):891-906. 
24. American Psychiatric Association. Diagnostic and Statistical Manual of Mental Disorders, Text Revision (DSM-IV-TRTM). Fourth ed. Washington, DC: APA (American Psychiatric Association); 2000:85-93.

25. Cornejo JW, Osio O, Sanchez Y, et al. Prevalence of attention deficit hyperactivity disorder in Colombian children and teenagers. Rev Neurol. 2005;40(12):716-722.

26. Bener A, Qahtani RA, Abdelaal I. The prevalence of ADHD among primary school children in an Arabian society. J Atten Disord. 2006; 10(1):77-82.

27. Wolraich ML, Hannah JN, Baumgaertel A, Feurer ID. Examination of DSM-IV criteria for attention deficit/hyperactivity disorder in a county-wide sample. J Dev Behav Pediatr. 1998;19(3):162-168.

28. Dulcan M. Practice parameters for the assessment and treatment of children, adolescents, and adults with attention-deficit/hyperactivity disorder. J Am Acad Child Adolesc Psychiatry. 1997;36(10 suppl): $85 \mathrm{~s}-121 \mathrm{~s}$.

29. Cantwell DP. Attention deficit disorder: a review of the past 10 years. J Am Acad Child Adolesc Psychiatry. 1996;35(8):978-987.

30. Polanczyk G, Caspi A, Houts R, Kollins SH, Rohde LA, Moffitt TE. Implications of extending the ADHD age-of-onset criterion to age 12: results from a prospectively studied birth cohort. $\mathrm{J} \mathrm{Am} \mathrm{Acad} \mathrm{Child}$ Adolesc Psychiatry. 2010;49(3):210-216.

31. Zhou KY, Gao MH, Yang CH, et al. An epidemiological survey of attention deficit hyper-activity disorder in school-age children in Shenzhen. Chin J Contemp Pediatr. 2012;14(9):689-692.

32. Guan BQ, Luo XR, Deng YL, et al. Prevalence of psychiatric disorders in primary and middle school students in Hunan Province. Zhongguo Dang Dai Er Ke Za Zhi. 2012;12(2):123-127.

33. Chen SZ, Zeng F, Dang HP. Incidence and related factors of ADHD in children of Guilin City. Chin J Clin Psychol. 2004;12:386-387.

34. Leung PW, Luk SL, Ho TP, Taylor E, Mak FL, Bacon-Shone J. The diagnosis and prevalence of hyperactivity in Chinese schoolboys. $\mathrm{Br} J$ Psychiatry. 1996;168(4):486-496.

35. Bird HR. Epidemiology of childhood disorders in a cross-cultural context. J Child Psychol Psychiatry. 1996;37(1):35-49.

36. Egan J. The bipolar puzzle-what does it mean to be a manic-depressive child? The New York Times. 2008 Sept 12; MM66.

37. Miller G. Psychiatry. Any thing but child's play. Science. 2010;327(5970): 1192-1193.

38. Olfson M, Blanco C, Wang S, Laje G, Correll CU. National trends in the mental health care of children, adolescents, and adults by officebased physicians. JAMA Psychiatry. 2014;71(1):81.
39. Schwarz A, Cohen S. More diagnoses of ADHD. Causing concern. The New York Times. 2013 Apr 1; A1.

40. Canino G, Alegria M. Psychiatric diagnosis - is it universal or relative to culture? J Child Psychol Psychiatry. 2008;49:237-250.

41. James A, Hoang U, Seagroatt V, Clacey J, Goldacre M, Leibenluft E. A comparison of American and English hospital discharge rates for pediatric bipolar disorder, 2000 to 2010. J Am Acad Child Adoles Psychiatry. 2014;53(6):614-624.

42. Visser SN, Danielson M, Bitsko RH, et al. Trends in the parent-report of health care provider - diagnosed and medicated attention-deficit/ hyperactivity disorder: United States, 2003-2011. J Am Acad Child Adoles Psychiatry. 2013;53(1):34-46.

43. Bussing R, Murphy TK, Storch EA, et al. Psychometric properties of the Treatment-Emergent Activation and Suicidality Assessment Profile (TEASAP) in youth with OCD. Psychiatry Res. 2013;205(3):253-261.

44. Sandberg S, McCann DC, Ahola S, Oja H, Paton JY, McGuinness D. Positive experiences and the relationship between stress and asthma in children. Acta Paediatr. 2002;91(2):152-158.

45. Rowland AS, Lesesne CA, Abramowitz AJ. The epidemiology of attention-deficit/hyperactivity disorder (ADHD): a public health view. Ment Retard Dev Disabil Res Rev. 2002;8(3):162-170.

46. Ambuabunos EA, Ofovwe EG, Ibadin MO. Community survey of attention-deficit/hyperactivity disorder among primary school pupils in Benin City, Nigeria. Ann Afr Med. 2011;10(2):91-96.

47. Cunningham CE, Barkley RA. The role of academic failure in hyperactive behaviour. J Learn Disabil. 1978;11(5):15-21.

48. Petermann F, Lepach AC. Klinische Kinderneuropsychologie [Clinical child neuropsychology]. Kindheit Und Entwicklung. 2007;16:1-6.

49. Greven CU, Rijsdijk FV, Asherson P, Plomin R. A longitudinal twin study on the association between ADHD symptoms and reading. $J$ Child Psychol Psychiatry. 2012;53(3):234-242.

50. Millstein RB, Wilens TE, Biederman J, Spencer TJ. Presenting ADHD symptoms and subtypes in clinically referred adults with ADHD. J Atten Disord. 1997;2:159-166.

51. Morgan AE, Hynd GW, Riccio CA, Hall J. Validity of DSM-IV ADHD predominantly inattentive and combined types: relationship to previous DSM diagnoses/subtype differences. $J$ Am Acad Child Adolesc Psychiatry. 1996;35(3):325-333.

52. Biederman J, Faraone S, Milberger S, et al. Predictors of persistence and remission of ADHD into adolescence: results from a four-year prospective follow-up study. J Am Acad Child Adolesc Psychiatry. 1996; 35(3):343-351.
Neuropsychiatric Disease and Treatment

\section{Publish your work in this journal}

Neuropsychiatric Disease and Treatment is an international, peerreviewed journal of clinical therapeutics and pharmacology focusing on concise rapid reporting of clinical or pre-clinical studies on a range of neuropsychiatric and neurological disorders. This journal is indexed on PubMed Central, the 'PsycINFO' database and CAS,

\section{Dovepress}

and is the official journal of The International Neuropsychiatric Association (INA). The manuscript management system is completely online and includes a very quick and fair peer-review system, which is all easy to use. Visit http://www.dovepress.com/testimonials.php to read real quotes from published authors. 